\title{
Scenarios for Knowledge Integration: Exploring Ecotourism Futures in Milne Bay, Papua New Guinea
}

\author{
E. L. Bohensky, ${ }^{1}$ J. R. A. Butler, ${ }^{2}$ and D. Mitchell ${ }^{3}$ \\ ${ }^{1}$ CSIRO Ecosystem Sciences Division and Climate Adaptation Flagship, Private Mail Bag, Aitkenvale QLD 4814, Australia \\ ${ }^{2}$ CSIRO Ecosystem Sciences Division and Climate Adaptation Flagship, GPO Box 2583, Brisbane, QLD 4001, Australia \\ ${ }^{3}$ Asia-Pacific Field Division, Pacific Island Program, Conservation International, 211 Alotau, Papua New Guinea
}

Correspondence should be addressed to E. L. Bohensky, erin.bohensky@csiro.au

Received 21 April 2010; Revised 16 August 2010; Accepted 5 October 2010

Academic Editor: Judith D. Lemus

Copyright () 2011 E. L. Bohensky et al. This is an open access article distributed under the Creative Commons Attribution License, which permits unrestricted use, distribution, and reproduction in any medium, provided the original work is properly cited.

\begin{abstract}
Scenario planning, a method for structured thinking about the future, offers an important tool for integrating scientific and stakeholder knowledge at different scales to explore alternative natural resource management and policy options. However, actual examples of such integration are rare. A scenario planning exercise was conducted in Milne Bay Province, Papua New Guinea, to integrate knowledge among scientists, ecotourism experts, and ecotourism stakeholders to explore possible futures for Milne Bay's nascent ecotourism industry. Four scenarios focused on climate change and technology, highlighting the risks and opportunities associated with rapid information exchange, and options to develop alternative ecotourism activities despite climate change impacts on natural assets. Although ecosystem-based management strategies were not investigated in detail by participants, all scenarios recognized and identified important cross-scale partnerships required to achieve sustainable management of natural resources and to promote ecotourism. An evaluation of changes in perceptions at the beginning and end of the scenario exercise suggests that participants became more aware of social and ecosystem processes occurring at broad spatial and temporal scales.
\end{abstract}

\section{Introduction}

Marine ecosystem management operates in a context of high uncertainty due to processes that occur at and across multiple spatial and temporal scales $[1,2]$. This is particularly so in the Pacific Islands, where uncertainty in marine management stems in part from local cultural norms that can influence resource use and conservation decisions [3-5] and a general lack of data to support decision-making $[6,7]$.

In this context of uncertainty, planning for the future presents a challenge and is confounded by complex system dynamics such as nonlinearity and reflexivity-people's actions in response to future expectations can, in fact, lead to a different future than they expected [8]. Furthermore, beliefs about the future may be based on different epistemologies or knowledge systems [9]. Indeed, because the future is yet to happen, there is no "true" state of the future and, therefore, alternative characterizations or images of the future that illustrate a range of possible states may collectively provide the most insight into what the future might hold [10].
Scenario planning is a structured process of exploring the future in situations when uncertainty is high and controllability is low [11]. Alternative scenarios produced through such a process are in effect conceptual models or stories that describe how the future may unfold. In such uncertain, uncontrollable situations, scenarios have an advantage over more quantitative models (such as systems dynamics or agent-based models) in their flexibility, transparency, and, utilization of narrative to describe possible futures in all their complexity. Well-suited to participatory processes where there is a need to engage stakeholders without scientific or technical backgrounds, scenarios have been used in a range of resource-dependent communities in Asia and Africa for a decade or more [12-14]. To our knowledge, scenarios have not been widely applied in marine ecosystem management in the Pacific.

Though scenarios are increasingly used to explore the future, there has been little consideration of their role in integrating knowledge of different stakeholders, including scenario developers (but see [15]), and of their potential 


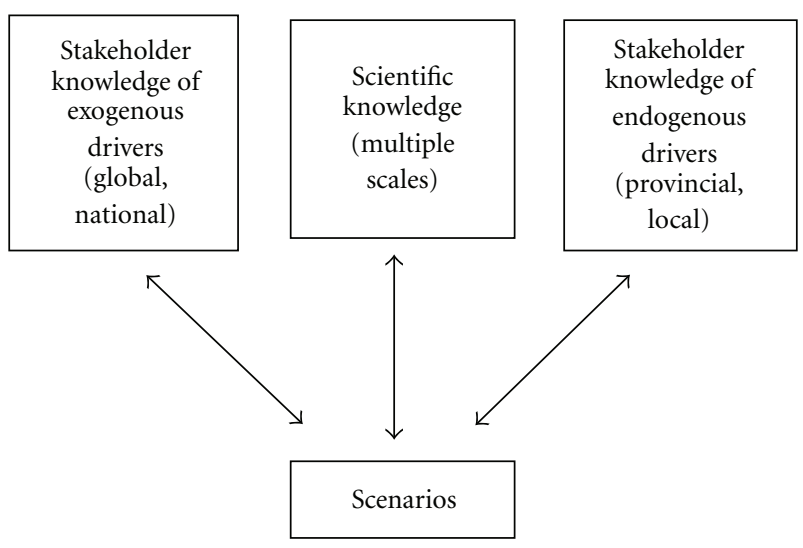

FIGURE 1: Process of knowledge integration through scenarios. The arrows extend in both directions to indicate an iterative process of information flows between the scenarios and the different knowledge sets.

as boundary objects; that is, they link individuals with different training, interests, and backgrounds [16]. Scenarios have at least two potential integrative abilities: first, they can integrate knowledge and underlying epistemologies of different actors, such as scientists, resource users, and decision-makers. While scientific knowledge can be obtained at multiple scales, from local to global, it often lacks detail and cultural context. Thus, even if future events can be predicted with reasonable confidence by scientific methods, it is difficult to predict how people will respond or indeed pre-empt these events. Scenarios, by bringing together participants' knowledge and scientific information in various forms, can produce a future understanding greater and better informed than any one information source alone. Second, it is difficult to predict how different events and human responses will interact across global, national, and local scales. Comprising information at multiple scales, scenarios help to identify drivers of change that are both exogenous and endogenous to the system of interest, as well as crossscale drivers, that are not possible to evaluate by looking at information from one scale alone. The effectiveness of scenarios for multiscale analysis of ecosystems and human well-being was demonstrated in several Millennium Ecosystem Assessment projects, for example, in Southern Africa, the Mediterranean, Caribbean, and Northern Highland Lake District in Wisconsin $[15,17,18]$.

The relationship between scenarios and knowledge is bidirectional; just as knowledge contributes to the building of scenarios, scenarios contribute to the expansion of knowledge (Figure 1). Scenarios can also be used to evaluate knowledge in several ways, by (1) indicating where knowledge needs to be updated as new information is available or perceptions of the future change, (2) assessing the relevance and credibility of scientific knowledge used to build scenarios, and (3) revisiting assumptions that underpin scenarios [18].

In this paper we view knowledge as comprising multiple realms of information, in line with Berkes' [19] description of a knowledge-belief-practice complex that includes not
TABle 1: Drivers of change for Milne Bay's ecotourism industry, from most to least frequently mentioned by participants as a negative or positive driver.

\begin{tabular}{lcc}
\hline Driver & Positive & Negative \\
\hline Education & 12 & - \\
Technology & 10 & 1 \\
Climate change & - & 9 \\
Overharvesting and exploitation & - & 9 \\
Population growth & - & 8 \\
Industrialisation & 2 & 6 \\
Information and media & 6 & 1 \\
Government system and structures & - & 5 \\
Infrastructure & 5 & - \\
Growth in demand for ecotourism & 5 & - \\
Accessibility/transport & - & 4 \\
Corruption & - & 4 \\
Legal framework & 3 & 1 \\
(Rising) costs of fuel & - & 3 \\
Disease introduction and spread & - & 3 \\
Multiculturalism & 1 & 2 \\
Values & 2 & - \\
Urbanisation & 1 & 1 \\
Agricultural practices & 1 & 1 \\
Migration to Milne Bay & - & - \\
Crime/law and order & - & - \\
Resource demand & & - \\
\hline
\end{tabular}

only traditional ecological knowledge but also environmental practices, social institutions, and world views. Knowledge also encompasses knowledge holders' perceptions of key drivers of future change and response options [20]. Much of the knowledge discussed in this paper relates to perceptions of the future which, despite the impossibility of "knowing" the future, are deeply rooted in individually and socially held knowledge [21, 22]. Knowledge systems are not always explicitly identified as such, and the integration process is often a subtle, tacit one.

This paper discusses the use of a scenario process to integrate knowledge to explore possible futures for the ecotourism industry in Milne Bay, Papua New Guinea. Milne Bay's high biophysical and cultural diversity-the essence of its ecotourism appeal-imply that ecotourism will achieve the most success if it is planned and undertaken in the vein of ecosystem-based management $[23,24]$; that is, it is managed at the provincial (i.e., landscape) scale and acknowledges social-ecological system complexity. An important imperative for knowledge integration exists in ecosystem-based management, which is inherently focused on management at multiple levels [25] and thus requires knowledge about the ecosystem to be drawn from different scales and, consequently, different knowledge sources. Scenarios provide a mechanism for integrating knowledge temporally (into the future) as well as spatially.

The scientific objective of the scenario process was to trial a method for better understanding of how the future is 
perceived by a particular stakeholder group, and the objective of the ecotourism industry was to better understand risks, opportunities, and strategies for future development. We explored knowledge integration through scenarios in two ways: (1) by bringing together scientific knowledge and provincial-scale stakeholder knowledge in a workshop and (2) by evaluating changes in perceptions before and after the scenario workshop. We highlight divergence in views that may need resolution and gaps where more information is needed, noting other scenario processes that have explored similar issues. Lastly, we discuss the utility of scenario planning for developing decision-making processes for marine ecotourism and multiscale ecosystem management strategies.

\section{Methods}

2.1. Study Area. Milne Bay Province, which includes the eastern end of mainland of Papua New Guinea (PNG) and some 435 islands (Figure 2), is an area of high national and global conservation significance due to its ecological diversity [26]. Though PNG's marine ecosystems are considered to be in excellent condition [27], degradation due to overharvesting is an acknowledged threat to marine resources in Milne Bay [28]. The past decade has seen community-based coastal and marine resource management and conservation advocated in the province $[28,29]$. Ecotourism is being promoted by nongovernment and PNG government organizations as a preferred form of economic development because it potentially provides sustainable livelihoods for communities based on nonconsumptive utilization of natural assets, while also generating an incentive for local communities to conserve these assets. Thus ecotourism is a means of ecosystem-based management that delivers ecological as well as livelihood and well-being benefits [24].

In this light, members of Milne Bay's nascent ecotourism industry have begun expressing an interest in learning how to establish sustainable ecotourism. There is also a desire in the province to place control of tourism in local hands. In the past, tourism in PNG has, in large part, been conducted by multinationals who often take the funds out of the country. In Milne Bay Province there is a push toward ecotourism, following local and international recognition that the province in particular offers unique natural features, wildlife, and culture that tourists demand. Compared to other provinces that have allowed international firms to deplete their resources without sharing profits, a more conservation-oriented ethic exists in Milne Bay. However, a lack of infrastructure and institutional capacity are noted as major challenges [29], compounded by factors that are largely beyond the province's control that can impact tourism such as recent global economic shocks and climate change.

2.2. Workshop with Ecotourism Stakeholders. In June 2008, an ecotourism workshop in Alotau, the provincial capital, brought together industry stakeholders, including ecotourism operators, representatives of the Milne Bay Tourism
Bureau, and representatives of nongovernmental organizations with an interest in ecotourism to discuss "big-picture" issues for the industry. Invitations to the workshop were sent to all known ecotourism stakeholders in the province, and twenty-one responded positively and attended. The workshop was facilitated by a locally based nongovernment organisation, with sessions run by two international scientists and two ecotourism experts. The workshop entailed a series of discussions over three days to discuss types of ecotourism, challenges faced, and approaches for understanding and overcoming these challenges. One of these sessions was devoted to a rapid (one-day) scenario-planning exercise to identify key drivers and uncertainties affecting the ecotourism industry, to consider alternative scenario storylines for its future, and implications for management of the natural assets underpinning the industry.

Following an introduction to the overall workshop goals, presentations were given by scientists and tourism experts on biodiversity conservation in Milne Bay, definitions and examples of ecotourism, the theory of scenario planning, and methods and examples of scenarios developed elsewhere. The scenario planning exercise built on previous experiences used to examine ecosystem services in a Southern African river basin and to explore alternative development trajectories for the Great Barrier Reef region [17, 30, 31]. The exercise involved a series of steps: (1) identifying a guiding question and timeline, (2) identifying drivers of change, (3) ranking drivers of change for importance and uncertainty, (4) identifying two axes of uncertainty and four scenario quadrants, (5) forming breakout groups to develop storylines for each of the four scenarios, and (6) presentation and discussion of the scenarios, including implications for managing ecotourism and ecosystems that support it.

The identification of a guiding question first required agreement on a definition of ecotourism. Ecotourism was defined as "responsible travel to natural areas that conserves the environment and improves the wellbeing of local people, and an enriching experience in which local communities' cultural relationship with their environment, developed over many generations, is shared by the guide with the traveller." In small groups, participants identified natural and cultural assets (marine and terrestrial) that they considered important for ecotourism on a map of Milne Bay Province (Figure 3). The group identified its guiding question as "Will it still be possible to have sustainable ecotourism in 2040?" The year 2040 was selected by asking participants to recall key events and trends in the past as well as considering scientific data and projections for population growth, climate change, and other variables that were highlighted in the presentations. Participants identified major changes such as collapse of the bêche-de-mer fishery, doubling of human population, changes in agricultural production, and PNG's independence, all having occurred within the past 30 years, serving as a frame of reference for envisioning the future. Thirty years also corresponds roughly to one generation, allowing participants to envision life when their children reach their age.

The group then identified drivers that might influence the outcome of the guiding question. Each participant was 


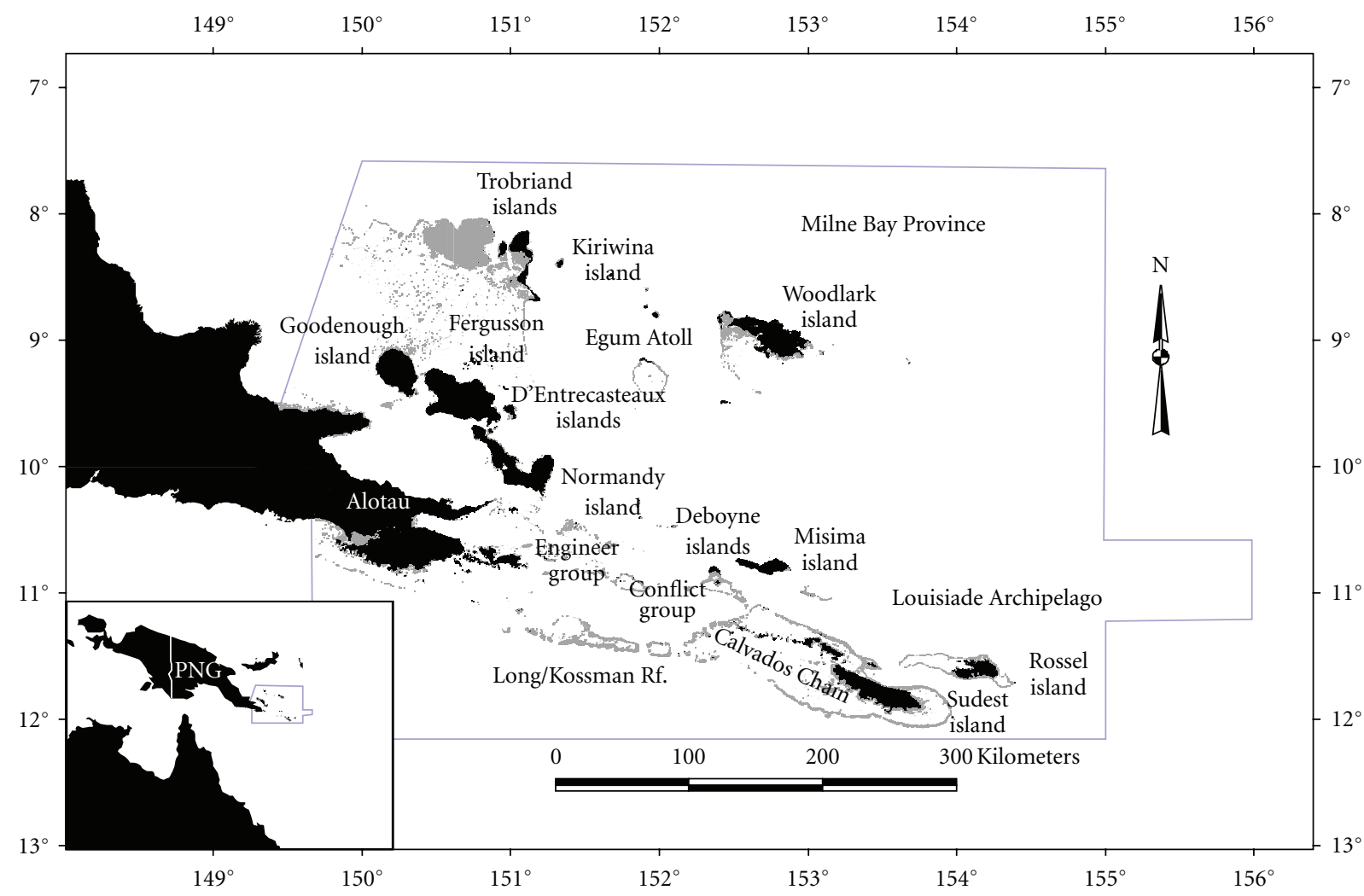

Figure 2: Map showing Milne Bay Province. Black areas represent dry land, and grey areas coral reefs and coastal habitats.

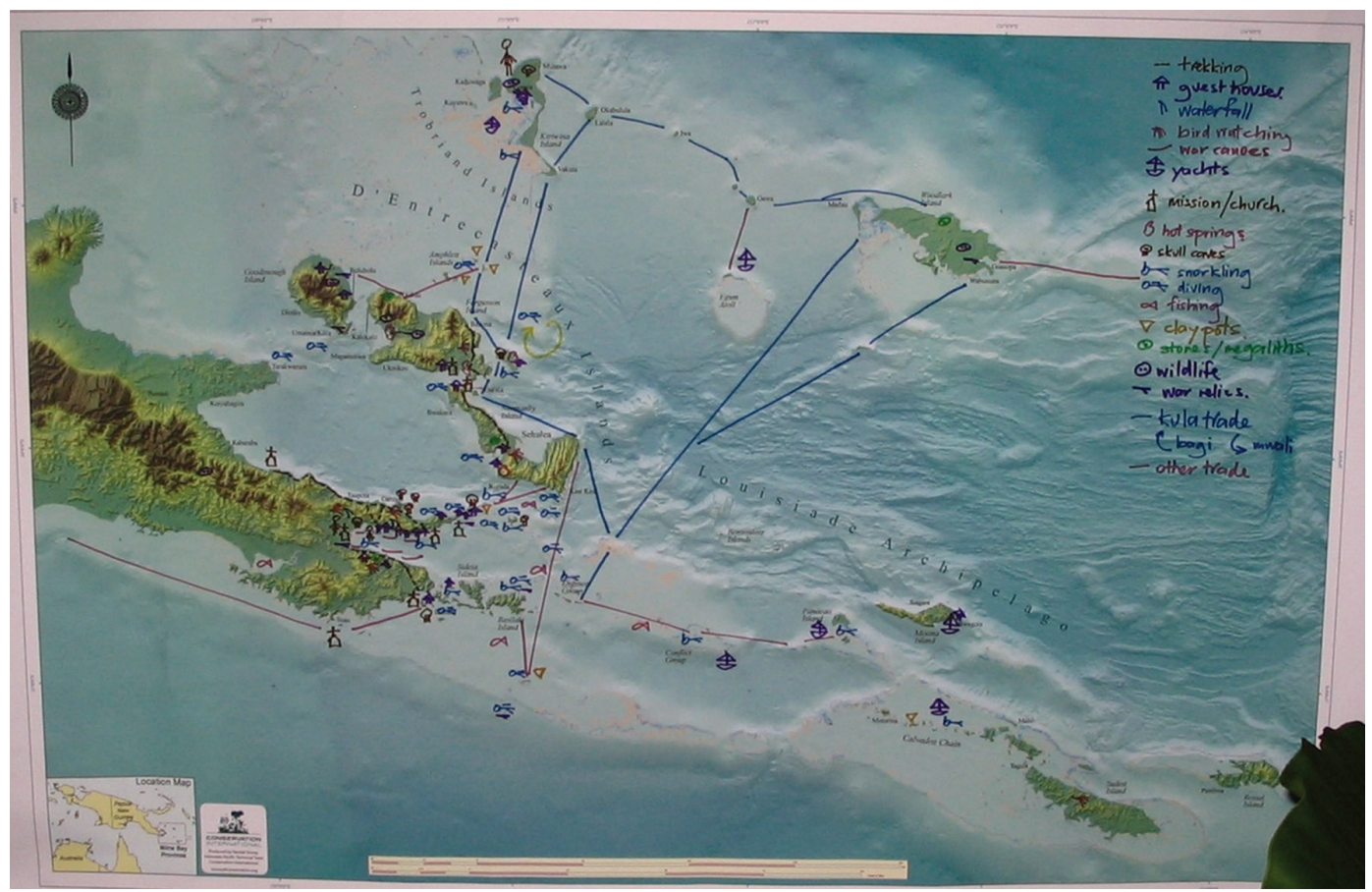

FIGURE 3: Composite map of important natural and cultural assets supporting ecotourism identified by participants. 
TABle 2: Perceptions of biggest threat to Milne Bay ecotourism, biggest opportunity for Milne Bay ecotourism and time required to establish a successful ecotourism industry in Milne Bay, pre- and post-scenario exercise.

\begin{tabular}{|c|c|c|}
\hline Biggest threat & $\begin{array}{l}\text { Number }(\%) \text { of } \\
\text { participants responding, } \\
\text { pre-exercise }\end{array}$ & $\begin{array}{l}\text { Number }(\%) \text { of } \\
\text { participants responding, } \\
\text { post-exercise }\end{array}$ \\
\hline Poor management of (eco)tourism industry & $5(27)$ & $1(5)$ \\
\hline Poor governance & $4(21)$ & $4(20)$ \\
\hline Extractive industry/overharvesting/exploitation & $3(17)$ & $3(15)$ \\
\hline Economy & $2(11)$ & $3(15)$ \\
\hline Geography & $1(6)$ & $0(0)$ \\
\hline Change in biophysical environment/climate & $1(6)$ & $8(40)$ \\
\hline Understanding and awareness & $1(6)$ & $0(0)$ \\
\hline Media & $1(6)$ & $0(0)$ \\
\hline Political will & $0(0)$ & $1(5)$ \\
\hline \multicolumn{3}{|l|}{ Biggest opportunity } \\
\hline Cultural link to environment & $5(28)$ & $3(16)$ \\
\hline Income for local communities & $3(17)$ & $2(11)$ \\
\hline Infrastructure (e.g., international flights, transportation) & $3(17)$ & $3(16)$ \\
\hline Marketing and promotion of Milne Bay & $3(17)$ & $1(5)$ \\
\hline Funding and support & $2(11)$ & $0(0)$ \\
\hline Biodiversity, endemism, uniqueness, and beauty of natural environment & $1(6)$ & $0(0)$ \\
\hline Training of tour guides & $1(6)$ & $3(16)$ \\
\hline Climate change & $0(0)$ & $1(5)$ \\
\hline Technology & $0(0)$ & $2(11)$ \\
\hline Marine activities (e.g., diving) & $0(0)$ & $2(11)$ \\
\hline Partnerships & $0(0)$ & $1(5)$ \\
\hline Friendly people of Milne Bay & $0(0)$ & $1(5)$ \\
\hline \multicolumn{3}{|l|}{ Time required to establish successful ecotourism industry } \\
\hline At least 1 year but less than 5 years & $2(12)$ & $1(6)$ \\
\hline At least 5 years but less than 10 years & $7(41)$ & $6(35)$ \\
\hline At least 10 years but less than 20 years & $7(41)$ & $6(35)$ \\
\hline At least 20 years & $1(6)$ & $4(24)$ \\
\hline
\end{tabular}

asked to write down the three drivers that they believed would be most influential for achieving sustainable ecotourism to 2040. Participants felt that it was necessary to distinguish positive and negative drivers, and it was agreed that each person would write down three of each type. These were displayed for the group and tabulated (Table 1). From these, participants selected climate change and technology as the two drivers that they felt would have the highest impact and were most uncertain. Education was more frequently mentioned than either of these as a positive driver, but there was thought to be less uncertainty associated with the future direction of education. In addition, overharvesting, while mentioned as frequently as climate change, was thought to have less uncertainty associated with its impacts.

Climate change and technology became the focal axes of the scenarios. The group identified unpredictable elements of climate change as changes in sea level rise, carbon credits, changes in temperature and extreme events, and their impacts on natural assets. Uncertain elements of technology were identified as the commitment of government to improve rural communications, impact on lifestyles, speed of adoption, market opportunities, cost, better sources of energy, micro-hydropower, the spread of environmental information, and government policies. To stimulate the development of the scenarios, the scenario facilitators suggested four possible ways that these two key uncertainties, climate change and technology, could combine.

(1) A climate change crisis happens in the near future and low-cost technology is available in Milne Bay Province.

(2) Climate change brings about gradual changes and low-cost technology is available.

(3) A climate change crisis happens in the near future and low-cost technology remains unavailable.

(4) Climate change brings about gradual changes and low-cost technology remains unavailable.

Four groups were formed, and each group was assigned to one of these combinations, with the task of sketching 
a brief, logical storyline, focusing on two questions: (1) under this scenario, how would you achieve sustainable ecotourism by 2040 ? and (2) what do you think are the most important collaborations or partnerships to achieve successful ecotourism in Milne Bay Province? The groups were also asked to name their scenario.

2.3. Evaluation of Participants' Perceptions before and after Scenarios. Little evaluation has been done of the impact of scenario processes in the stakeholder communities in which they are used [16] and in influencing participants' perceptions of the future and their ability to envision the future. We were interested in gauging the effect of the scenario process on participants' responses to questions about future ecotourism; therefore, one day before and one day after the exercise, participants were asked to individually answer the following open-ended questions.

(1) What do you think is the biggest threat to ecotourism in Milne Bay Province?

(2) What do you think is the biggest opportunity for ecotourism in Milne Bay Province?

(3) How long will it take to establish a successful ecotourism industry in Milne Bay Province?

Responses were analyzed for thematic content, and in the case of question (3), quantitative content (i.e., the number of years). Themes were identified and responses were categorized according to the most appropriate theme or themes. Responses with similar themes were grouped into a smaller number of categories (i.e., "Increase in extractive industry" and "Oil palm, mining, and logging" were both categorized as "Extractive industry/overharvesting/exploitation"). Responses in each category were then tallied.

\section{Results}

The working groups developed four scenarios based on interactions of the most uncertain drivers, the speed and nature of climate change, and the availability of low-cost, readily adoptable technology. Summaries of the four scenario narratives are presented below. As these were written for the purpose of presentation and discussion amongst the four groups, narratives were written in an informal style, with references to locally familiar place-names, for example. Below the participants' original text was preserved as much as possible, except for where clarification was needed.

\subsection{Four Futures for Milne Bay}

3.1.1. Down but Not Out, In Fact, Better Than Ever: New Life (Climate Crisis, Technology Available). High-level seas surge, flooding local roads. Coastal zones and small islets disappear under water. High rainfall events cause rivers to flood and there is severe erosion. Coastal homes are lost. The central business district of Alotau is flooded. The road to East Cape is cut, and the North Coast fringe is lost to sea level rise. Thanks to low-cost technology, everybody has access to mobile phones, even on the islands, and some have internet. Thus they are aware of the risks of climate change and are ready to respond.

The effect of the climate change "crisis" is to stimulate action, to start a new life. Looking to 2040, there will be a need for proper planning to relocate infrastructure, roads, health centers, schools, villages, and guesthouses. There will be mangrove replanting, Coast Care, conservation, education, awareness, and a focus on practical onground actions. An emphasis will be placed on environment and community life. Business activities will be greencertified and eco-friendly, links will be made into carbon markets, with support from overseas funds. Energy will be provided by a mix of hydropower, wind generation, solar, and biodiesel. Internet advertizing and promotion of the region as an ecotourism destination will be standard practice-Milne Bay's green culture becomes its selling point.

Because of the need to relocate villages and services and build new infrastructure, the climate change crisis presents an opportunity to incorporate technology appropriately into villages. This requires partnerships with organizations specializing in appropriate technology, the environmental, forestry, sustainable agriculture, planning, civil engineering, electrical and communication sectors, and with donor agencies (such as AusAid, the European Union, Japan International Cooperation Agency and the United Nations), carbon traders, and the Government of PNG.

\subsubsection{Kula Connections: Sailing to the Future (Gradual} Climate Change, Technology Available). Climate change is a risk, but in the absence of an immediate crisis, there is time to prepare for it. The Kula Ring, a traditional system of trade between the islands, is reborn in the Information Age. Technology allows better information exchange, networking between tourism businesses and partners (e.g., NGOs), and education, energy, and transport improvements. With this information exchange comes a coordinated approach to diversifying ecotourism products.

There is a risk of increased information exchange that leads to the loss of cultural uniqueness, authenticity, and the ownership of ecotourism opportunities to foreign investors, but this can be addressed through legislation and increased awareness, again using networks and partnerships to assist. Technology can also support use of alternative energy, fuelefficient transport, better communication between operators and with partners, tourist markets, and global connections. This is complemented by better education at the village level, including about ecotourism.

3.1.3. Escape to East Cape: Island Hoppers (Climate Crisis, Technology Unavailable). Sea levels continue to rise at the current rate. Low atolls disappear, including Survivor Island at Haloweya and small islands in the Conflict and Engineer groups. Sea currents become stronger, jeopardizing travel by traditional sailing canoes, and making diving and snorkelling unsafe. There is migration from the affected islands to the mainland, creating tension between those displaced and 


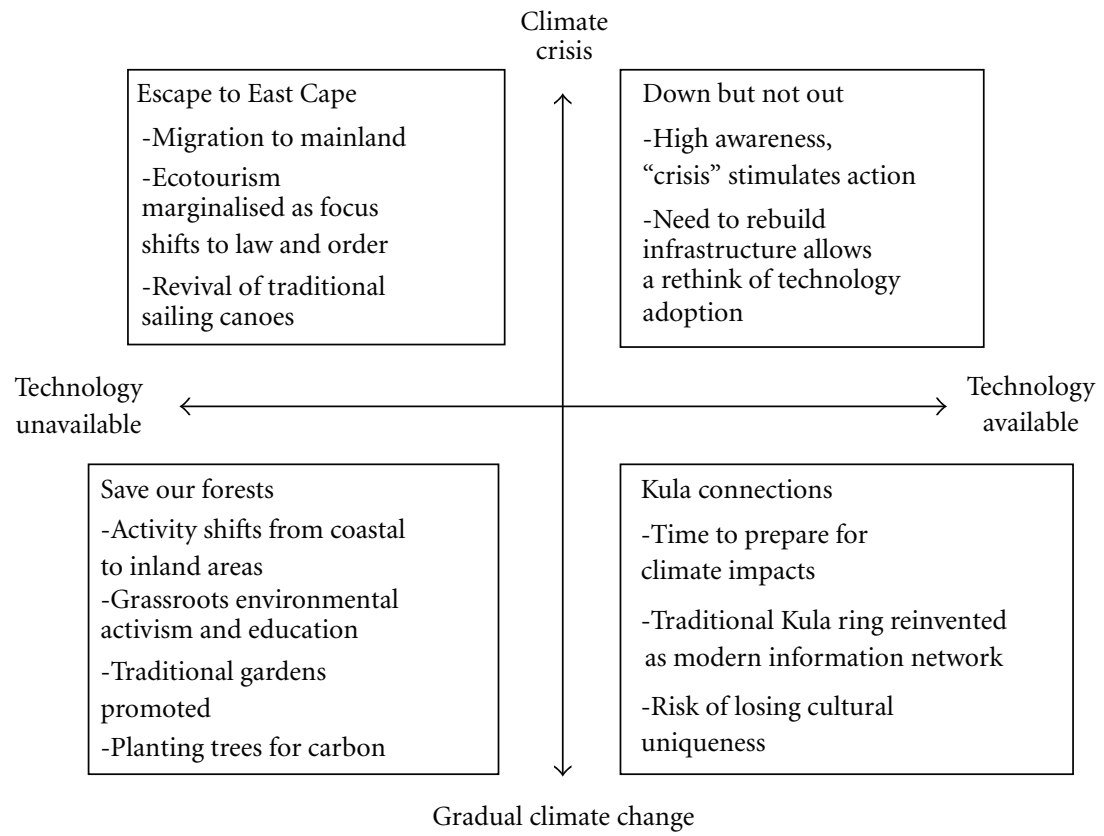

FIGURE 4: Four scenarios based on interactions of the most uncertain drivers identified by the stakeholder group: the speed and nature of climate change and the availability of low-cost, readily adoptable technology.

residents. Some tourism attractions, such as white sandy beaches and critical wildlife habitat, are lost.

Ecotourism becomes a marginal industry. There is a lack of effective communication, information, and transportation for tourists and locals alike. However, around Milne Bay the use of traditional canoes increases, and interest is revived in promoting cultural tourism, but the canoes need to be better built so that they are more reliable-especially without a mobile phone network for emergency calls. Tourism persists, but in a cautious "island-hopping" style; visitors consist only of the few most adventurous explorers.

Priorities are law and order to maintain security and conflict reduction. However, education and awareness are high on the agenda, and Alotau becomes a hub of research activity on climate change impacts in the Pacific. Actions include (1) forging relationships between groups at multiple scales to share information, much of it through word-ofmouth, (2) proactive lobbying of government and NGOs for funding to improve communications, (3) improving government action to resettle migrants, and (4) introducing food crops tolerant of salinity rise for local food supplies and tourists.

3.1.4. Save Our Forests (Gradual Climate Change, Technology Unavailable). Milne Bay reverts to low-technology, grassroots approaches to environmental awareness and conservation. Anticipating rising sea levels, people shift their activities from coastal to inland areas. Wise use of traditional farming - whereby gardens are passed down to childrenis promoted, rather than clearing virgin forest and causing hillside soil erosion. People plant more mangroves and traditional trees and quickly engage in the carbon trade and lobby for government policies to help protect forests before more severe climate changes occur. Strategies also include teaching environmental issues in schools, including global climate change and carbon trading, using media to raise awareness, preserving cultural values of skull caves, awareness of sacred sites and protocols, preserving wildlife, teaching young ones to respect the environment, and training resource owners, NGOs, churches, and Local Level Government.

3.2. Comparison of Pre- and Post-Scenario Workshop Responses. The pre- and post-scenario perceptions regarding biggest threats and opportunities to ecotourism in Milne Bay Province and the time required to establish a successful ecotourism industry in Milne Bay Province are shown in Table 2.

Climate change and related environmental change was the most frequently mentioned threat at the conclusion of the scenario exercise ( $40 \%$ of participants), compared to only one participant $(6 \%)$ mentioning it at the start. Poor management of the ecotourism industry was much less frequently mentioned (from $27 \%$ before to $5 \%$ after) while economy was slightly more frequently mentioned (from $11 \%$ to $15 \%$ ) and extractive industry and poor governance remained similar. Understanding and awareness, media, and geography, collectively mentioned by $18 \%$ of the participants at the start of the exercise, were not mentioned at the conclusion, while political will was mentioned by $5 \%$.

Among the biggest opportunities identified before the exercise were the cultural link to the environment $(28 \%)$, income for local communities (17\%), infrastructure (17\%), and marketing and promotion of Milne Bay (17\%). After the exercise, an equal number of participants (16\%) mentioned the cultural link to the environment, infrastructure, and training of tour guides. Post-exercise responses were more 
TABLE 3: Action items identified during the workshop to support goals identified in scenario process. Each item was assigned to an individual or group to lead.

(1) Create a list of web-links and other contact details and circulate to workshop participants.

(2) Create a list of inbound tour operators from the Port Moresby airport with contact details for Milne Bay Tourism Bureau (MBTB)

use.

(3) Provide examples of Tourism Profile Surveys for operators to consider (via MBTB).

(4) Create a list of free web tools operators can use (always advising MBTB so they are aware).

(5) Distribute photo of map created on Day 1 of workshop.

(6) Circulate presentations to all participants.

(7) Circulate report from this workshop.

(8) Provide copy of the image of the decimated landscape of Madagascar shown in the workshop as an example of poorly-managed tourism, to raise awareness.

(9) Develop a Code of Practice that differentiates ecotourism businesses from mainstream tourism.

(10) Establish system of Dive Fees, following aspects of Raja Ampat (Indonesia) model, through the following steps:

(a) Build awareness with the Minister

(b) Develop 5-year strategy

(c) Work with policymakers to write legislation

(11) Begin data collection to undertake Value Chain Analysis of ecotourism industry (analysis of long-term changes that might affect individual operators and their connections to others in the market).

(12) Meeting of participants with MBTB to discuss collaboration in the future and any role they might play to assist, identify further actions and draft visitors' survey.

diverse, with climate change, technology, marine activities (e.g., diving), partnerships, and friendly people of Milne Bay all noted as "opportunities", although not identified before.

More participants (30\%) stated that it would take longer ( $>10$ years) to establish a successful ecotourism industry in Milne Bay after the exercise than before, when only $12 \%$ stated that it would take this long. After the exercise, four participants said that it would take at least 20 years.

\section{Discussion}

4.1. Interpretation of Scenarios. The scenario workshop revealed four conceptual models of Milne Bay Province: one a crisis-inspired, technology-embracing paradigm shift (Down but Not Out), one a high-technology, informationpropelled future, in which people are proactive but cautious (Kula Connections), one championing a back-tobasics, grassroots activism (Save our Forests), and one of struggling through, with increasing tensions accompanying rising seas (Escape to East Cape). The four scenarios revealed both risks and opportunities associated with the two key drivers, climate change and technology. For example, while climate change impacts were initially viewed as threatening, participants noted opportunities associated with climate change such as the development of alternative ecotourism activities, and for the region to become a center for climate change research. Conversely, while low-cost technology was initially viewed as beneficial, participants recognized threats to ecotourism posed by rapid information exchanges over high-speed communication networks. Interestingly, the two scenarios that dealt with a climate change crisis explored solutions to possible problems in the most detail.
It appeared that the terms "climate change" and "technology" were overwhelmingly interpreted by the scenario groups as, respectively, "sea level rise" and "information." The narrow focus is not unexpected given the short time that groups were given to work on their scenarios but may also reflect an understanding of these issues that is limited to actual experiences, such as the loss of coastline and infrastructure, and the importance of radios, mobile phones, and internet. In particular, slower or more subtle impacts of climate change on ecotourism, such as coral bleaching, were not explicitly identified by participants. As a possible consequence of this narrow focus, management strategies for vulnerable natural assets underpinning ecotourism were not explored in any detail. Only two scenarios, "Down but Not Out" and "Save Our Forests" discussed ecosystem management, and actions were largely limited to community scale intervention such as mangrove planting to protect coastlines from sea level rise. In an extended exercise, scientific information could provide more detailed dynamics of the driving forces and projected impacts of climate change and technology while provincial stakeholders could provide locally meaningful contextual details such as placenames, language, history, cultural norms, as well as detailed observations over a long time period [21]. By integrating both forms of knowledge, a wider range of implications of these drivers can be addressed [15].

Scenarios have been used in other studies to explore tourism and its vulnerability to climate change. For example, the Caribbean Sea Ecosystem Assessment evaluated changes in Caribbean ecosystems and ecosystem services and options for responding to these changes [15]. Reliance on tourism was identified as a major uncertainty around which scenario 
storylines were developed. New marine diseases and sea level rise were discussed as particular threats to the tourism industry as consequences of a changing climate. Scenarios have also been used to explore the future role of tourism and ecotourism in a developed country context and, specifically, how ecosystem degradation impacts on tourism appeal and, in turn, regional economies and property values $[11,31]$.

The role of technology in supporting tourism development does not seem to be well-explored in scenario exercises, although technology has frequently been identified as a key driver in many scenario processes [31], likely due to the magnitude of technological impacts and their uncertainty in influencing the future. Probing a wide array of direct and indirect technological developments and their potential consequences for ecotourism in Milne Bay would be a significant, but necessary, undertaking in follow-up scenario work.

Discussion of the scenarios suggested that building social networks and partnerships between members of the ecotourism industry and affiliated organizations, such as international tourism bodies and nongovernmental organizations, is particularly important. Participants also discussed the need to adopt long-term plans and visions for the ecotourism sector, to avoid progressing down an undesirable pathway from which there is no easy return, and to reach consensus on aspects of tourism regulations, marketing, and promotion so that standards can be developed. Action items were identified at the close of the workshop to support these goals (Table 3 ).

4.2. Insights and Future Directions. The use of scenarios, like other participatory modelling processes, to integrate knowledge about the future stipulates careful consideration of objectives and outcomes [32]: is it to support local people to understand scientific information, to persuade local people to adopt scientists' views, to elicit local perspectives for the value they add to scientific understanding, to learn from each other, or to test methodologies? Scenarios can effectively do all of the above. In our case, the scenario process and evaluation indicate that scenarios helped participants to think about the future in new and different ways, to reveal where views about the future diverge, and where understanding is lacking.

Our evaluation of changes in perceptions at the beginning and end of the scenario development process suggests that among participants, changes in perceptions occurred regarding major drivers of change and effective responses: awareness increased of processes occurring at broad spatial and temporal scales and the need for longer-term planning. In interpreting these results, it should be noted that (1) no standard definitions were given for the terms "collaboration," "partnership," and "successful;" (2) participants' interpretations of the question about length of time required to establish a successful ecotourism industry appeared to vary, with some responding about individual tourism operations and some about the industry as a whole; and (3) scenarios were not the only activity undertaken during the workshop. Despite these possible shortcomings, the evaluation does provide at least a general picture of how beliefs about the drivers of tourism may have evolved over the course of the workshop.

We offer a few insights on the role of scenarios in integrating knowledge. First, we acknowledge that scenarios rarely integrate information explicitly, but they do so implicitly by building stories based on different information sources. Scenarios risk being a "knowledge dump": a process of "free-floating" [33] exploration whereby issues of accuracy and precision, weighting, standardization, and resolution of discrepancies do not often receive attention. That said, there is a trade-off between quantification and transparency and flexibility. It may be useful to develop both quantitative and qualitative scenarios to suit a range of purposes [15].

Second, the sequence of information insertion is important. There is a need to gauge perspectives on perceptions of future change before and after information is presented, and we have included such an evaluative component in our ongoing research. However, there is another trade-off between giving too little information to enable participants to address a full range of drivers that impact them, risking biased or unfounded conclusions, and giving too much information, risking confusion or disinterest. Finding the right balance is key. A related challenge emerges in evaluating perspectives and how they change without actually influencing them before the evaluation takes place.

While scenarios can help to build consensus [34], a diversity of knowledge and perspectives on the future can be of great value for learning [15]. Future uncertainty means that surprise is likely, and the most robust strategy is often to invest in a range of options. For this reason, ample space and time is necessary to accommodate differences in opinion.

The experience above lays the groundwork to further develop and refine the scenarios for application to ecotourism and broader ecosystem management in Milne Bay, where the scenarios approach as a future exploration and knowledge integration tool remains novel. In follow-up scenario work, the future visions described in the workshop could be developed in parallel with future visions at the scale of the ecotourism operators and their communities or villages. The village-scale perspective could provide a local reality check for the scientific aspects of the scenarios, while also offering a level of detail beyond that afforded at the provincial scale. A next step for using these visions might entail presenting the four regional scenarios to local stakeholders, eliciting their views and responses and feeding these back to the regional scenarios. Alternatively, scenario development could begin at the village scale and be presented to provincial stakeholders. Such cross-scale scenario development is useful for effectively dealing with the complex problems presented in futures analysis and tends to increase the relevance of scenarios at all scales of interest [18].

4.3. Development of Ecosystem-Based Management to Support Ecotourism. Ecotourism is widely promoted in Milne Bay as a potential panacea for reconciling the need to improve livelihoods with the conservation of globally recognized marine and terrestrial biodiversity values [29]. In spite of 
the benefits of ecotourism being implicitly understood by the stakeholders at the workshop, there was little discussion of the need for ecosystem-based management per se to conserve the natural assets underpinning the industry. Specific management actions were only mentioned in two scenarios, and these largely related to community scale planting of mangroves to protect coastline from sea level rise. However, elements of ecosystem-based management were present in the scenarios and deliberations that followed, such as the need to plan ecotourism at a large landscape scale that incorporates a range of terrestrial and marine ecosystems, and for ecotourism operators to involve and ensure benefits to local villages to discourage activities that are ecologically detrimental.

The scenarios workshop may have had a subtle influence on progressing ecosystem-based management of marine and terrestrial assets by raising awareness of broader temporal and spatial scales. The importance of cross-scale partnerships was recognized, and specific stakeholders identified, in all four scenarios. These were mentioned in terms of promoting ecotourism and sustainable natural resource management, and specific post-workshop actions were identified to develop them. Such partnerships are known to be crucial for the successful development of ecotourism in developing countries, since they provide multiple sources of knowledge, financial, human, and social capital [35], and are a prerequisite for establishing adaptive co-management of complex social-ecological systems $[36,37]$. Consequently our scenario planning approach may have accelerated the process of establishing ecosystem-based management in Milne Bay by increasing awareness and social networks amongst the ecotourism stakeholders at the workshop and identifying further partnerships necessary for consolidating the sustainable development of the industry.

\section{Acknowledgments}

The authors thank participants in the Alotau ecotourism workshop and CSIRO and Conservation International for funding and logistics. Elva Castino and Nina Kolbe are thanked for contributions to the workshop and Mombi Onesimo for follow-up discussions. An earlier version of this paper was presented at MODSIM09 (The Modelling and Simulation Society of Australia and New Zealand), Cairns, Australia, in July 2009. Alifereti Tawake, Thomas Stevens, and three anonymous reviewers are thanked for their reviews of the manuscript.

\section{References}

[1] J. A. Wilson, "Matching social and ecological systems in complex ocean fisheries," Ecology and Society, vol. 11, no. 1, article 9, 2006.

[2] J. Wilson, "Scientific uncertainty, complex systems, and the design of common-pool institutions," in The Drama of the Commons, T. D. E. Ostrom, N. Dolsăk, P. C. Stern, S. Stovich, and E. U. Weber, Eds., pp. 327-360, Committee on the Human Dimensions of Global Change, National Research Council, National Academy Press, Washington, DC, USA, 2002.
[3] R. E. Johannes, "Government-supported, village-based management of marine resources in Vanuatu," Ocean and Coastal Management, vol. 40, no. 2-3, pp. 165-186, 1998.

[4] S. Foale and B. Manele, "Social and political barriers to the use of Marine Protected Areas for conservation and fishery management in Melanesia," Asia Pacific Viewpoint, vol. 45, no. 3, pp. 373-386, 2004.

[5] C. Y. Bartlett, C. Manua, J. Cinner et al., "Comparison of outcomes of permanently closed and periodically harvested coral reef reserves," Conservation Biology, vol. 23, no. 6, pp. 1475-1484, 2009.

[6] R. E. Johannes, "The case for data-less marine resource management: examples from tropical nearshore finfisheries," Trends in Ecology and Evolution, vol. 13, no. 6, pp. 243-246, 1998.

[7] D. Zeller, S. Booth, P. Craig, and D. Pauly, "Reconstruction of coral reef fisheries catches in American Samoa, 1950-2002," Coral Reefs, vol. 25, no. 1, pp. 144-152, 2006.

[8] S. O. Funtowicz and J. R. Ravetz, "Science for the post-normal age," Futures, vol. 25, no. 7, pp. 739-755, 1993.

[9] G. Gallopín, "Planning for resilience: scenarios, surprises and branch points," in Panarchy: Understanding Transformations in Human and Natural Systems, L. Gunderson and C. S. Holling, Eds., pp. 361-392, Island Press, Washington, DC, USA, 2002.

[10] G. Gallopín, A. Hammond, P. Raskin, and R. Swart, Branch Points: Global Scenarios and Human Choice, Stockholm Environment Institute, Stockholm, Sweden, 1997.

[11] G. D. Peterson, G. S. Cumming, and S. R. Carpenter, "Scenario planning: a tool for conservation in an uncertain world," Conservation Biology, vol. 17, no. 2, pp. 358-366, 2003.

[12] E. Wollenberg, D. Edmunds, and L. Buck, "Using scenarios to make decisions about the future: anticipatory learning for the adaptive co-management of community forests," Landscape and Urban Planning, vol. 47, no. 1-2, pp. 65-77, 2000.

[13] D. B. Gurung and R. W. Scholz, "Community-based ecotourism in Bhutan: expert evaluation of stakeholder-based scenarios," International Journal of Sustainable Development and World Ecology, vol. 15, no. 5, pp. 397-411, 2008.

[14] E. I. Enfors, L. J. Gordon, G. D. Peterson, and D. Bossio, "Making investments in dryland development work: participatory scenario planning in the Makanya Catchment, Tanzania," Ecology and Society, vol. 13, no. 2, article 42, 2008.

[15] E. Bennett and M. Zurek, "Integrating epistemologies through scenarios," in Bridging Scales and Knowledge Systems: Concepts and Applications in Ecosystem Assessment, W. V. Reid, F. Berkes, T. Wilbanks, and D. Capistrano, Eds., pp. 275-294, Island Press, Washington, DC, USA, 2006.

[16] Y. Garb, S. Pulver, and S. Vandeveer, "Scenarios in society, society in scenarios: toward a social scientific analysis of storyline-driven environmental modeling," Environmental Research Letters, vol. 3, no. 4, Article ID 045015, 8 pages, 2008.

[17] Millennium Ecosystem Assessment, Ecosystems and Human Well-Being: Synthesis, Island Press, Washington, DC, USA, 2005.

[18] R. Biggs, C. Raudsepp-Hearne, C. Atkinson-Palombo et al., "Linking futures across scales: a dialog on multiscale scenarios," Ecology and Society, vol. 12, no. 1, article 17, 2007.

[19] F. Berkes, Sacred Ecology: Traditional Ecological Knowledge and Resource Management, Taylor \& Francis, Philadelphia, Pa, USA, 1999.

[20] J. P. Brosius, "What counts as local knowledge in global environmental assessments and conventions?" in Bridging Scales and Knowledge Systems: Concepts and Applications in Ecosystem Assessment, W. V. Reid, F. Berkes, T. J. Wilbanks, and 
D. Capistrano, Eds., pp. 129-144, Island Press, Washington, DC, 2006.

[21] F. Berkes, J. Colding, and C. Folke, "Rediscovery of traditional ecological knowledge as adaptive management," Ecological Applications, vol. 10, no. 5, pp. 1251-1262, 2000.

[22] I. Davidson-Hunt and F. Berkes, "Learning as you journey: Anishinaabe perception of social-ecological environments and adaptive learning," Conservation Ecology, vol. 8, no. 1, 2003.

[23] K. K. Arkema, S. C. Abramson, and B. M. Dewsbury, "Marine ecosystem-based management: from characterization to implementation," Frontiers in Ecology and the Environment, vol. 4, no. 10, pp. 525-532, 2006.

[24] O. R. Young, G. Osherenko, J. Ekstrom et al., "Solving the crisis in ocean governance place-based management of marine ecosystems," Environment, vol. 49, no. 4, pp. 20-32, 2007.

[25] P. Olsson, C. Folke, and T. P. Hughes, "Navigating the transition to ecosystem-based management of the Great Barrier Reef, Australia," Proceedings of the National Academy of Sciences of the United States of America, vol. 105, no. 28, pp. 9489-9494, 2008.

[26] T. B. Werner, A Rapid Biodiversity Assessment of the Coral Reefs of Milne Bay Province, Papua New Guinea, Conservation International, Washington, DC, USA, 1998.

[27] P. Seeto, Conservation Needs Assessment Report, Conservation International, Alotau, Papua New Guinea, 2001.

[28] J. Kinch, Stakeholder Participation Plan for the Milne Bay Community-Based Coastal and Marine Conservation Program, Conservation International, Alotau, Papua New Guinea, 2001.

[29] J. King and J. Bartlett, Milne Bay Province Model Province Five Year Tourism Plan, Global Tourism and Leisure Pty, Sydney, Australia, 2006.

[30] E. L. Bohensky, B. Reyers, and A. S. van Jaarsveld, "Future ecosystem services in a Southern African river basin: a scenario planning approach to uncertainty," Conservation Biology, vol. 20, no. 4, pp. 1051-1061, 2006.

[31] I. Bohnet, E. Bohensky, C. Gambley, and J. Waterhouse, Future scenarios for the Great Barrier Reef Catchment, CSIRO, Water for a Healthy Country National Research Flagship Canberra, 2008.

[32] T. Lynam, W. de Jong, D. Sheil, T. Kusumanto, and K. Evans, "A review of tools for incorporating community knowledge, preferences, and values into decision making in natural resources management," Ecology and Society, vol. 12, no. 1, article 5, 2007.

[33] R. A. Slaughter, "From forecasting and scenarios to social construction: changing methodological paradigms in futures studies," Foresight, vol. 4, no. 3, pp. 26-31, 2002.

[34] A. Kahane, “The Mont Fleur scenarios," Deeper News, vol. 7, 1992.

[35] F. Berkes, "Community-based conservation in a globalized world," Proceedings of the National Academy of Sciences of the United States of America, vol. 104, no. 39, pp. 15188-15193, 2007.

[36] D. R. Armitage, R. Plummer, F. Berkes et al., "Adaptive comanagement for social-ecological complexity," Frontiers in Ecology and the Environment, vol. 7, no. 2, pp. 95-102, 2009.

[37] F. Berkes, "Evolution of co-management: role of knowledge generation, bridging organizations and social learning," Journal of Environmental Management, vol. 90, no. 5, pp. 16921702, 2009. 

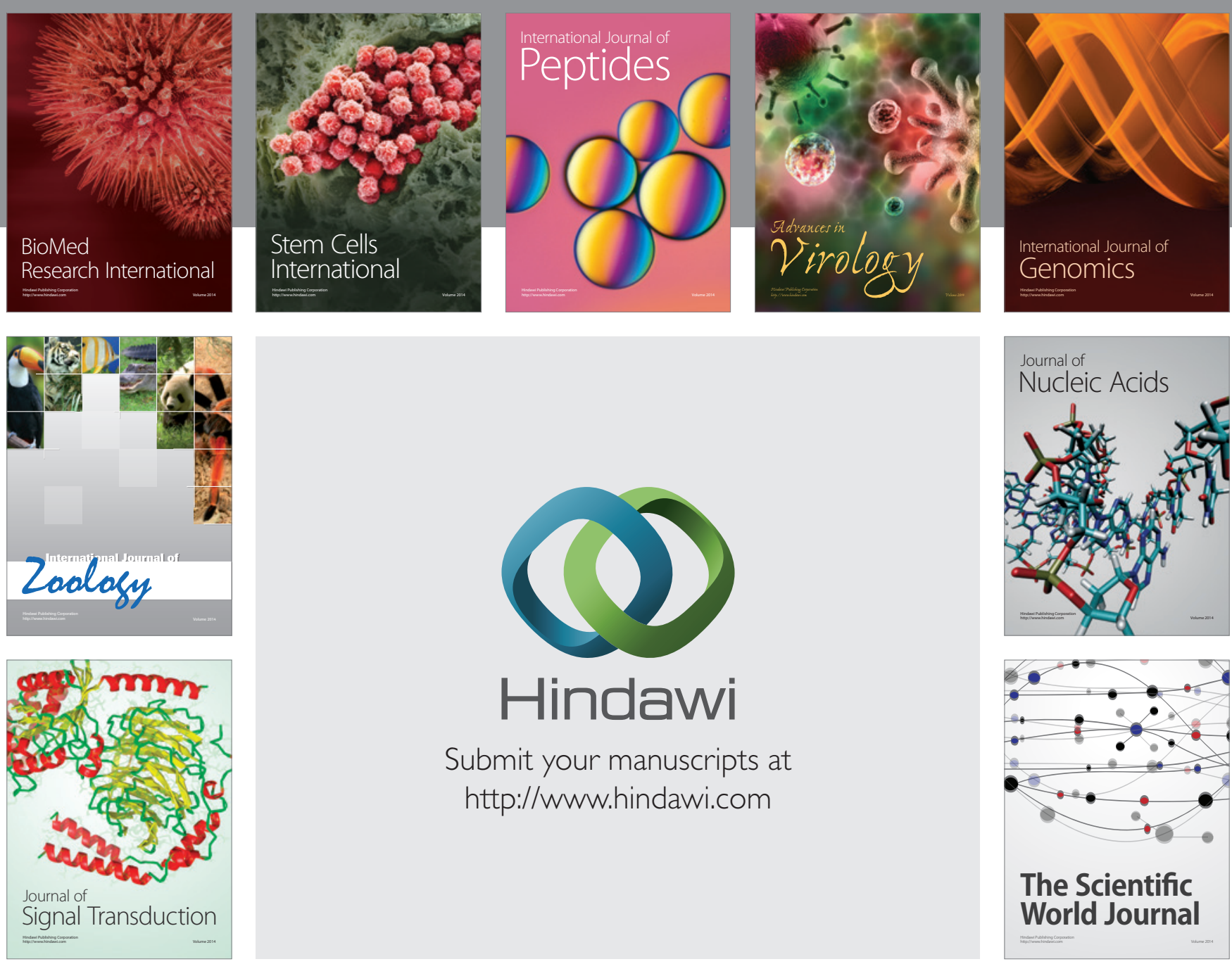

Submit your manuscripts at

http://www.hindawi.com
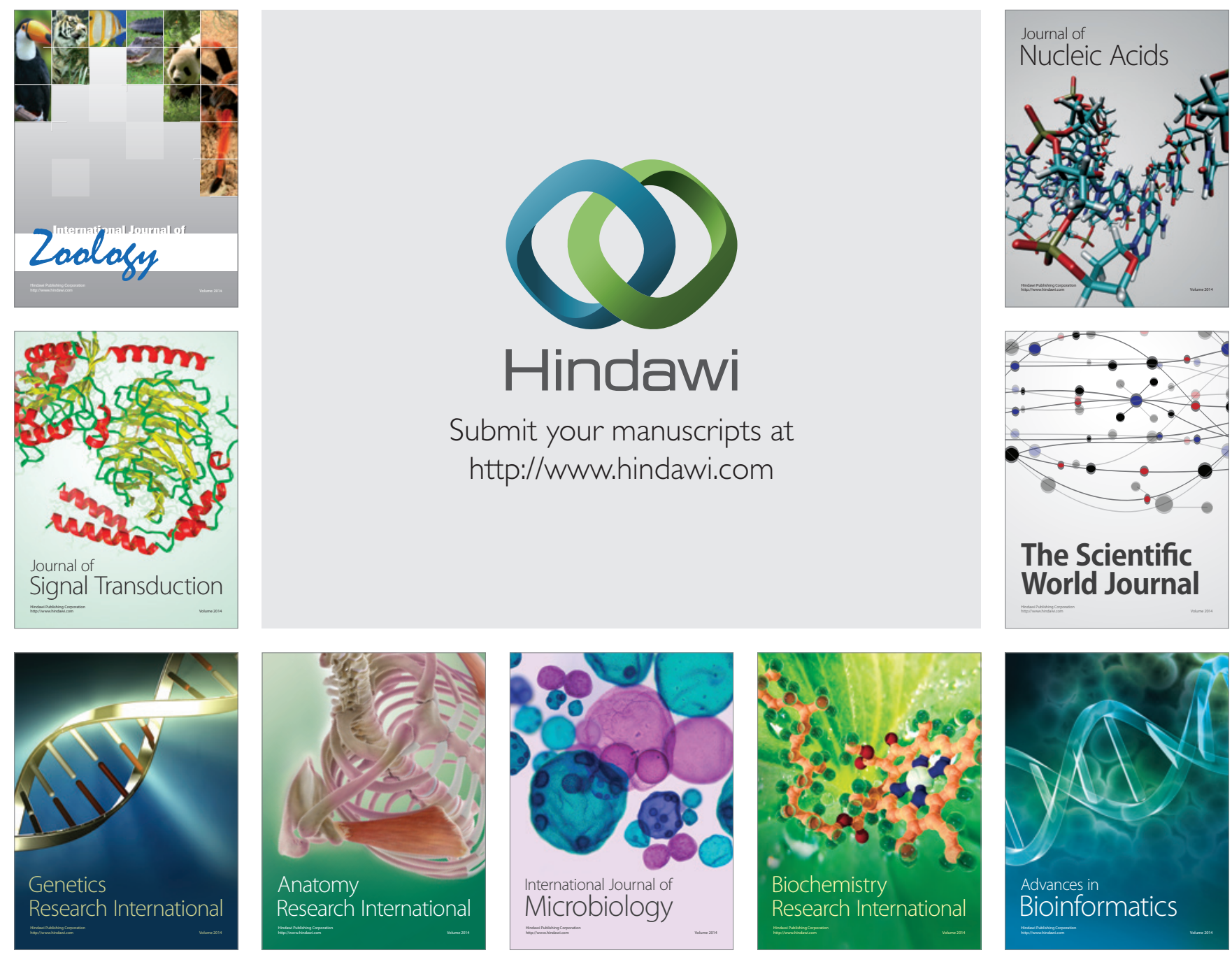

The Scientific World Journal
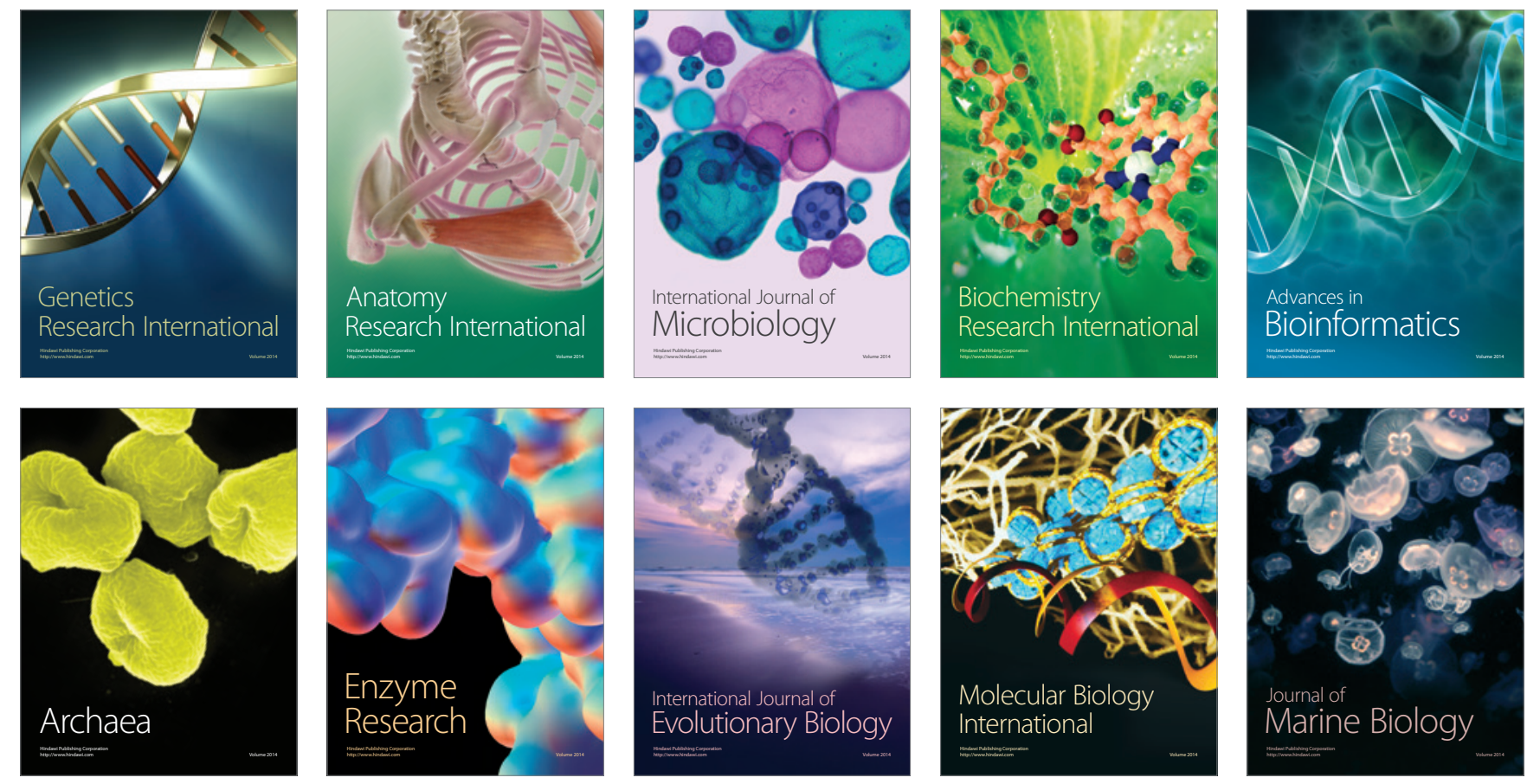